Document downloaded from:

http://hdl.handle.net/10251/51600

This paper must be cited as:

Samper Madrigal, MD.; Petrucci, R.; Sánchez Nacher, L.; Balart Gimeno, RA.; Kenny, JM. (2015). New environmentally friendly composite laminates with epoxidized linseed oil (ELO) and slate fiber fabrics. Composites Part B: Engineering. 71:203-209. doi:10.1016/j.compositesb.2014.11.034.

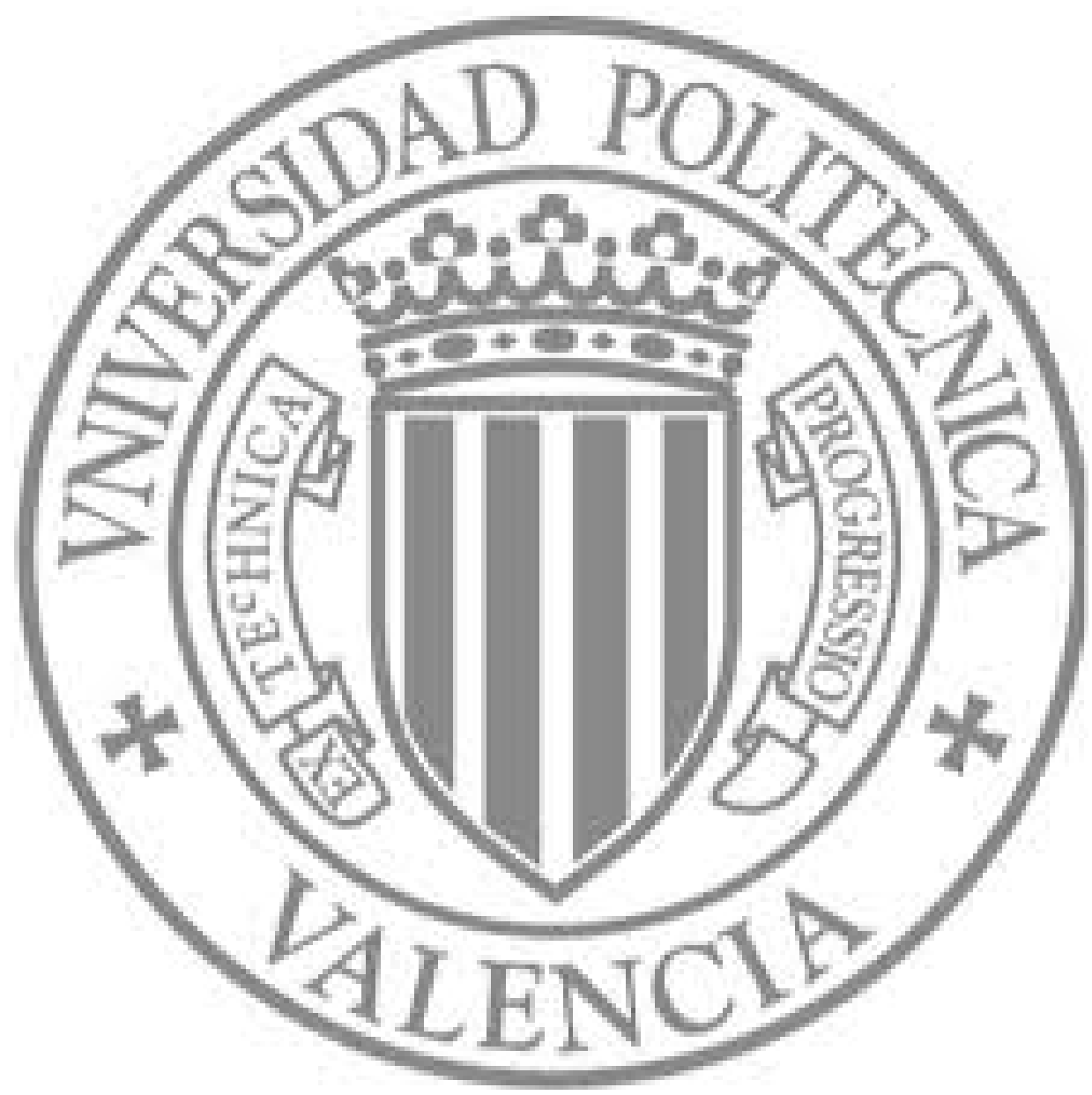

The final publication is available at

http://dx.doi.org/10.1016/j.compositesb.2014.11.034

Copyright Elsevier 


\title{
"New environmentally friendly composite laminates with epoxidized linseed oil (ELO) and slate fiber fabrics"
}

\author{
M.D. Samper ${ }^{\text {a }}$, R. Petrucci ${ }^{b}$, L. Sánchez-Nacher ${ }^{a}$, R. Balart ${ }^{a, 1}$, J.M. Kenny ${ }^{b}$ \\ ${ }^{a}$ Instituto de Tecnología de Materiales (ITM) \\ Universitat Politècnica de València (UPV) \\ Plaza Ferrándiz y Carbonell s/n, 03801, Alcoy, Alicante, Spain \\ ${ }^{b}$ Materials Engineering Center \\ University of Perugia
}

Località Pentima Bassa, 21, 05100 Terni, Italy

\begin{abstract}
This work focuses on the development of new composite laminates based on the use of epoxidized linseed oil (ELO) as matrix and reinforcement fabrics from slate fibers with different silane treatments. The curing behavior of the ELO resin is followed by differential scanning calorimetry (DSC) and the gelation is studied by oscillatory rheometry and gel-time. Composites laminates of ELO matrix and slate fabrics are manufactured by Resin Transfer Molding (RTM) and the mechanical properties of the composite laminates are tested in tensile, flexural and impact conditions. The effects of different silane coupling agents on fiber-matrix interface phenomena are studied by scanning electron microscopy (SEM). As in other siliceous fibers, silane treatment leads

\footnotetext{
${ }^{1}$ Corresponding author: Tel.: 9665284 21; Fax: 966528433
}

E-mail address: $\underline{\text { rbalart@mcm.upv.es }}$
\end{abstract}


to improved mechanical performance but glycidyl silane treatment produces the optimum results as the interactions between silanized slate fiber and epoxidized linseed oil are remarkably improved as observed by scanning electron microscopy (SEM).

Keywords: A. Fabric/textiles; A. Laminates; B. Mechanical properties; E. Resin transfer molding (RTM); E. Surface treatments

\section{Introduction.}

Slate rocks are generated by metamorphism of clay sediments under the action of high pressure and temperatures. The main feature of slate is preferential orientation of components in parallel planes (foliation) which allows easily obtaining slate sheets [1]. For this reason, slate is widely used as building material: tiles, cladding, floors, etc. Manufacturing of these building components generates great amounts of wastes coming from extraction and cutting such as dust and chips which have been recently considered as reinforcing materials in particle filled polymer composites [2-4] and cement mortars $[5,6]$. The slate fiber composition $[4,5,7-9]$ is similar to that of glass and basalt fibers, being the main components $\mathrm{Al}_{2} \mathrm{O}_{3}, \mathrm{SiO}_{2}, \mathrm{CaO}, \mathrm{MgO}, \mathrm{K}_{2} \mathrm{O}, \mathrm{Fe}_{2} \mathrm{O}_{3}[10,11]$. In the last years, basalt fiber has been increasingly studied as a candidate to glass fiber substitution in composites [10, 12-15]. Some research works have focused on the use of slate particles as reinforcing fillers in polymers [2]; nevertheless, to the best of our knowledge, there are not reports published on polymer matrix composites based on slate fiber fabrics since the weaving process is still being optimized.

On the other hand, the combination of an organic polymer matrix with an inorganic reinforcement such as siliceous fibers needs the use of fiber pre-treatments in order to improve the fiber-matrix interaction to promote a coupling effect between both 
components. This coupling effect improves load transfer from the matrix to the fiber thus leading to good mechanical performance. In order to improve fiber-matrix interactions it is possible to functionalize the fiber surface by using, among others, plasma techniques [16-18], maleic anhydride [2] or coupling agents such as amines [19, 20] or mostly silanes $[3,4,12,21]$.

Conventional matrices for composite laminates are petroleum-based thermosetting resins. Despite this, the increasing concern about environment preservation and the problematic related to petroleum depletion has led to the development and study of new materials from renewable resources with the aim of lightening the carbon footprint [22-25]. Among the wide variety of potential bioresources for polymers, vegetable oils (VOs) are gaining interest; VOs composition is based on triglyceride structures which are composed of three different fatty acids linked to a glycerol base molecule. The most common vegetable oils are composed of fatty acids with 14-22 carbon atoms and each fatty acid typically can content between 0 and 3 carbon-carbon double bonds. In particular, linseed oil (LO) is one of the vegetable oils with more carbon-carbon double bonds per triglyceride with an average value of 6.6 which can be selectively functionalized due to their reactivity [26]; for this reason, linseed oil is one of the best candidates for bio-based thermosetting resins synthesis. Linseed oil can be functionalized by an epoxidation process to form oxirane rings as a consequence of the reaction of double bonds with peracids. The epoxidation process of linseed oil gives epoxidized linseed oil (ELO) with similar properties to some petroleum-based epoxy resins. ELO can be crosslinked as any conventional epoxy resin by using amines $[23,27]$ and anhydrides [28, 29]. In the last years some researches have focused on the use of ELO as matrix for composite materials in combination with different reinforcements [29-31]. 
The research reported here focuses on the development of environmentally friendly composite laminates based on epoxidized linseed oil (ELO) matrix and slate fabrics obtained from slate fibers manufactured by melt spinning from wastes. Slate fabrics are manufactured from rovings by manual weave and their potential as reinforcement in laminates is evaluated. The research also explores the possibilities of conventional Resin Transfer Molding (RTM) techniques to manufacture these innovative composite laminates.

\section{Experimental.}

\subsection{Materials.}

Epoxidized linseed oil (ELO) supplied by Traquisa S.A. (Barcelona, Spain) with an epoxy equivalent weight (EEW) of $178 \mathrm{~g} \mathrm{equiv}^{-1}$ was used as base resin for composites. ELO was crosslinked with methyl nadic anhydride (MNA) supplied by Sigma Aldrich (Schneldorf, Germany) with an anhydride equivalent weight (AEW) of 178.2 g equiv $^{-1}$. The complete resin formulation was set to an EEW:AEW ratio of 0.9 as this ratio gives good balanced properties as observed in previous works [32]; higher ratios could lead to fragility. Furthermore $1 \mathrm{wt} . \%$ propanediol (PDO) supplied by Coralim Aditivos (Ribaroja del Turia, Spain) was used as hydroxyl groups supplier to start the reaction and 2 wt.\% of 1-methyl imidazole (1MI) supplied by Sigma-Aldrich (Schnelldorf, Germany) was used as accelerator.

The reinforcing fabrics were obtained in a handloom by using slate fiber rovings supplied by Mifibra S.L. (Ourense, Spain) with a brown color, a monofilament diameter between $15-23 \mu \mathrm{m}$ and an elastic modulus of about $50 \mathrm{GPa}$. The final fabrics had an average surface density of $500 \mathrm{~g} \mathrm{~m}^{-2}$. These slate fabrics were subjected to surface modification with different coupling agents (silanes, titanates and zirconates) supplied 
by Sigma-Aldrich (Schnelldorf, Germany): A: [3-(2-aminoethylamino)propyl]-

trimethoxysilane; B: trimethoxy[2-(7-oxabicyclo[4.1.0]hept-3-yl)ethyl]silane; C:

zirconium (IV) bis(diethyl citrate)dipropoxide and D: titanium(IV) (triethanolaminato)isopropoxide solution.

\subsection{Silane treatment of slate fibers.}

Before treatment with coupling agents, slate fabrics were subjected to a burning process at $300{ }^{\circ} \mathrm{C}$ for $2 \mathrm{~h}$ to remove previous sizings used for manufacturing. After this, water-ethanol $(50: 50 \mathrm{v} / \mathrm{v})$ solutions containing $1 \mathrm{wt} . \%$ coupling agent were prepared and were magnetically stirred to promote hydrolysis and homogenization. Subsequently, slate fabrics were immersed into the corresponding solution for $10 \mathrm{~min}$ and after this, slate fabrics were extracted from the solution, washed several times with distilled water and, finally, they were dried in an oven at $40^{\circ} \mathrm{C}$ for $12 \mathrm{~h}$.

Five different slate fabrics were obtained with the following designation: Slate TT (slate fabric with thermal-burning treatment and no coupling agent), Slate A (slate fabric treated with coupling agent A), Slate B (slate fabric treated with coupling agent B), Slate C (slate fabric treated with coupling agent C) and Slate D (slate fabric treated with coupling agent D).

\subsection{Composite manufacturing.}

Composite laminates were manufactured by Resin Transfer Molding (RTM) using a Hypaject MKII from Plastech Thermoset Tectonics Ltd. (Gunnislake, UK) connected to a vacuum pump in the vent point of the mold to improve evacuation of air and prevent the inclusion of air bubbles in the composite. Composite laminates were 
obtained by stacking four slate fabrics (same direction $-0 / 90^{\circ}$ ); the average slate fiber content was 56 wt.\%. The RTM conditions are summarized in Table 1.

\section{Table 1}

\subsection{Characterization of the curing process of ELO.}

The curing process of the epoxidized linseed oil (ELO) was followed by dynamic differential scanning calorimetry (DSC) in a Mettler Toledo 821e (Mettler Toledo S.A.E., Barcelona, Spain). Aprox. $10 \mathrm{mg}$ of the liquid formulation (ELO+MNA ratio 1:0.9 + 1 wt. $\%$ PDO + 2 wt. $\%$ 1-MI) were placed into a standard $40 \mu \mathrm{l}$ Al crucible and subjected to a temperature cycle from $30^{\circ} \mathrm{C}$ up to $300{ }^{\circ} \mathrm{C}$ at a heating rate of $5^{\circ} \mathrm{C}$ $\min ^{-1}$. After this stage, a cooling step from $300{ }^{\circ} \mathrm{C}$ to $30^{\circ} \mathrm{C}$ at $-10^{\circ} \mathrm{C} \mathrm{min}{ }^{-1}$ was applied followed by a second heating cycle from $30{ }^{\circ} \mathrm{C}$ to $350{ }^{\circ} \mathrm{C}$ at $5{ }^{\circ} \mathrm{C} \min ^{-1}$. All three steps were carried out in nitrogen atmosphere (flow rate $60 \mathrm{~mL} \mathrm{~min}^{-1}$ ).

The curing behavior was also studied by plate-plate oscillatory rheometry (OR) in an AR-G2 rheometer from TA Instruments (New Castle, DE, USA). Two aluminum parallel plates with a diameter of $25 \mathrm{~mm}$ were used and the curing behavior was studied in isothermal conditions at $90,100,110$ and $120{ }^{\circ} \mathrm{C}$. Isothermal tests were carried out with a maximum deformation $(0.1 \%)$ at a constant frequency of $1 \mathrm{~Hz}$. The gel-time was taken from the crossover point in which $G^{\prime}=G^{\prime}$. The gel time is representative of the curing process and it is of great importance to define manufacturing conditions. In addition to the gel time determination, the apparent activation energy $\left(E_{a}\right)$ of the gelation process was estimated by taking into account that the gel time is inversely proportional to the reaction rate constant $(\mathrm{k})$

$$
t_{g e l}=C \cdot \frac{1}{k}
$$


Where $t_{\text {gel }}$ is the gel time, $C$ is a constant and $k$ is the reaction rate constant which follows an Arrhenius dependence on temperature:

$$
k=A \cdot e^{\left(-\frac{E_{a}}{R T}\right)}
$$

Where $A$ is the frequency factor, $E_{a}$ is the apparent activation energy, $R$ is the universal gas constant and $T$ is the absolute temperature.

By combining eq. (1) and (2) we obtain:

$$
t_{g e l}=C^{\prime} \frac{1}{e^{\left(-\frac{E a}{R T}\right)}}
$$

and applying natural logarithms:

$$
\operatorname{Ln}\left(t_{g e l}\right)=C^{\prime \prime}+\frac{E_{a}}{R \cdot T}
$$

A plot of $\operatorname{Ln}\left(t_{\text {gel }}\right)$ versus $1 / T$ takes the form of a linear expression $y=a+b \cdot x$ where $a=$ $C$ " and $b=E_{a} / R$, so that, it is possible to estimate the apparent activation energy by a linear plot of the experimental data of $\operatorname{Ln}\left(t_{g e l}\right)$ vs $1 / T$.

\subsection{Mechanical testing.}

Tensile tests were carried out by following ASTM D3039-08 in a universal test machine Instron mod. 3382 with a load cell of $100 \mathrm{kN}$ and a crosshead rate of $2 \mathrm{~mm}$ $\min ^{-1}$. With regards to flexural tests, a universal test machine Lloyd mod. $30 \mathrm{~K}$ with a load cell of $500 \mathrm{~N}$ at a crosshead speed of $1.7 \mathrm{~mm} \mathrm{~min}^{-1}$ was used as suggested by ASTM D790-10. Mechanical properties in impact conditions were evaluated in a Charpy's pendulum of 6 J from Metrotec (San Sebastián, Spain).

Differences in mechanical results were statistically analyzed by one-way analysis of variance (ANOVA) using Origin Pro 8 software. To identify which groups were significantly different from other groups, means comparison was done using the Tukey's test with a 95\% confidence level. 


\subsection{Microscopic analysis of the fractured surface.}

Samples of composites were cryofractured using liquid nitrogen and subsequently subjected to a sputtering process with gold $(10-25 \mathrm{~nm}$ thickness $)$ in vacuum conditions prior to their analysis to increase their electrical conductivity. They were observed in a scanning electron microscope JSM 5410 from JEOL (Peabody, United States of America), operated at an acceleration voltage of $10 \mathrm{kV}$.

\section{Results and discussion.}

\subsection{Characterization of the curing of epoxidized linseed oil (ELO).}

The curing process of ELO with cyclic anhydrides is similar to that of a conventional epoxy resin being the location of oxyranic rings in ELO the main difference. Oxirane rings in ELO are not located in terminal positions and this leads to lower reactivity. In a first stage, hydroxyl groups (from propanediol) react with the cyclic anhydride to give a monoester and a carboxylic acid group. Then, this carboxylic acid reacts with oxirane ring in the ELO to form a diester and an additional hydroxyl group which can newly react with a cyclic anhydride successively to form a highly crosslinked thermosetting structure.

The evolution of the curing process of ELO with cyclic anhydride (MNA) was carried out in dynamic conditions by differential scanning calorimetry (DSC). Fig. 1 shows the calorimetric graph with the first heating (on liquid sample) cycle and the second heating (on cured sample) cycle. Curing of epoxy resins with cyclic anhydrides leads to high performance cured materials but crosslinking needs high temperatures [33, 34]. The curing process starts at $143.4{ }^{\circ} \mathrm{C}$ and ends at about $231.2{ }^{\circ} \mathrm{C}$ with a peak temperature of $175.7^{\circ} \mathrm{C}$. The second heating does not give any exothermic peak thus indicating full curing during the first cycle. 


\section{Figure 1}

By using oscillatory rheometry (parallel plates' geometry) it is possible to obtain the gel time for different isothermal curing cycles at $90,100,110$ and $120^{\circ} \mathrm{C}$. At the initial stages of the curing process the phase angle $(\delta)$ is close to $90^{\circ}$ which indicates typical liquid behavior with a phase angle of $90^{\circ}$ between the applied stress $(\sigma)$ and the obtained deformation $(\gamma)$. The onset of the curing process is located at the time range in which a clear decrease in phase angle occurs; this continuous decrease is representative for the evolution of the crosslinking process until the phase angle $(\delta)$ reaches values close to $0^{\circ}$ which indicates no phase angle between the applied stress and the corresponding deformation which is typical of an elastic solid material, thus giving evidence of the end of the crosslinking process. The gel time can be determined as the middle point between the initial liquid mixture and the fully cured solid and so, it can be estimated as the time to reach the midpoint between the phase angle for a liquid $(\delta=$ $\left.90^{\circ}\right)$ and the phase angle for an elastic solid $\left(\delta=0^{\circ}\right)$. Therefore, this conventional gel time corresponds to a phase angle of $45^{\circ}$ which can also be calculated from the crossover point between the storage modulus ( $\left.\mathrm{G}^{\prime}\right)$ and the loss modulus (G’) as $\tan \delta=$ G'/G'.

Fig. 2 shows a comparative plot of the curing process of epoxidized linseed oil (ELO) obtained by oscillatory rheometry at different isothermal temperatures. The gel time, estimated as the crossover point between $G^{\prime}$ and G" strongly decreases as the isothermal temperature increases. The gel time plays a key role in the manufacturing process. As the curing process occurs, an increase in viscosity is produced due to formation of high molecular weight structures as a consequence of the crosslinking reactions. This has a negative effect on the resin flow which can produce inappropriate 
filling of the mold cavity. For these reasons, the selected temperature was $100{ }^{\circ} \mathrm{C}$ which represents equilibrium between a good processability in the liquid form, good gel time to ensure a good filling of the mold cavity and air bubble removal avoiding, on the other hand, long curing cycles. It is important to remark that high temperatures promote a quick crosslink process that can be negatively associated to the appearance of deleterious internal stresses.

\section{Figure 2}

In addition to gel time calculation, the obtained values are useful to estimate the apparent activation energy $\left(\mathrm{E}_{\mathrm{a}}\right)$ of the gelation process using eq. 4. The gel time is remarkably reduced as the temperature increases changing from $9376 \mathrm{~s}$ for a curing temperature of $90^{\circ} \mathrm{C}$ up to $1497 \mathrm{~s}$ for a curing temperature of $120^{\circ} \mathrm{C}$. As it can be seen in Figure 3, values of $\operatorname{Ln}\left(\mathrm{t}_{\mathrm{gel}}\right)$ vs $1000 / \mathrm{T}$ can be linearly adjusted with a regression parameter of $\mathrm{R}^{2}=0.99$ thus leading to an apparent activation energy, $\mathrm{E}_{\mathrm{a}}$ of $71.2 \mathrm{~kJ} \mathrm{~mol}^{-1}$. This value is similar to some apparent activation energy values found in the literature. Qi Tao et al. determined Ea of an epoxy resin cured with anhydride with a value of $70.6 \mathrm{~kJ} \mathrm{~mol}^{-1}$ and this value was reduced up to $62.8 \mathrm{~kJ} \mathrm{~mol}^{-1}$ by the addition of modified kaolinite. [35] J. Karger-Kocsis et al. determined the Ea of a conventional epoxy resin with a value of $52.9 \mathrm{~kJ}$ mol-1 and the Ea of a vegetable oil-based epoxy resin (ESBO) with a value of $72.3 \mathrm{~kJ}$ mol-1 thus indicating which is in total agreement with the obtained results due to the lower reactivity of oxirane groups in epoxidized vegetable oils compared to many petroleum-based epoxies with oxirane groups placed in terminal positions. [36] 


\section{Figure 3}

\subsection{Mechanical characterization of ELO-slate fabrics composite laminates.}

The mechanical performance of ELO-slate composite laminates was studied in tensile, flexural and impact tests. The mechanical behavior of the composite laminates is summarized in Table 2, where it can be observed that the tensile strength is slightly higher for all composites with slate fabrics subjected to treatment with coupling agents with regard to the untreated fabric, but de difference is not significant $(\mathrm{p}<0.05)$. With regard to the elastic modulus a similar tendency is observed as the elastic modulus of laminates with untreated slate fibers is close to $21.9 \mathrm{GPa}$ and the maximum elastic modulus values were obtained for ELO-slate B (25.6 GPa) and for ELO-slate D (25.2 GPa) $(\mathrm{p}>0.05)$, thus indicating improved fiber-matrix interactions.

With regard to the flexural behavior, the flexural strength increases from values of about 299.2 MPa for composite laminates without any coupling agent up to values over $400 \mathrm{MPa}$ for composite laminates with slate fibers treated with glycidyl silane (ELO-slate B) with a significant relative increase higher than $33 \%(\mathrm{p}>0.05)$. In addition to this, it is important to note that all the coupling agents led to improved flexural properties with respect to the composite with the unmodified slate fabric. With regard to the flexural modulus we observe a slight variation with closer values from 18.4 GPa (ELO-slate TT) up to $20 \mathrm{GPa}$ for the ELO-slate B composite, but the difference is not significant $(\mathrm{p}<0.05)$.

Regarding to the absorbed energy values obtained in Charpy's impact tests, in general terms, the composite laminates with coupling agents offer better impact response; this is representative of a good fiber-matrix interaction which allows good load transfer from matrix to fiber which is more evident in impact conditions. The 
impact energy for composites with untreated slate fabric is $66.0 \mathrm{~kJ} \mathrm{~m}^{-2}$ and once again, composite laminates with slate fiber coupled with glycidyl silane (ELO-slate B) gives the maximum results with an absorbed energy of $77.9 \mathrm{~kJ} \mathrm{~m}^{-2}$ which represents a relative increase of $18 \%$.

Table 2

By taking into account tensile and flexural properties, optimum mechanical resistant properties are obtained for composites with slate fibers previously coupled with glycidyl silane and titanate (ELO-slate B and ELO-slate D) respectively. By comparing these results with other studies on composite materials with similar fiber content (glass, basalt, carbon) we see that slate composites offer slightly higher performance than those obtained with glass and basalt fibers but, obviously, slate fiber composites are far from carbon fiber composites. Guermanzi et al. used epoxy resin as matrix and both glass and carbon fibers as reinforcement with a fiber content in the 48 66 wt.\% range. Tensile strength values of the glass fiber composites was close to 186 MPa while the tensile strength for carbon fiber composites varied in the 242-312 MPa range. With regard to flexural properties, the flexural strength was $240 \mathrm{MPa}$ and 600 $\mathrm{MPa}$ for glass and carbon fiber composites respectively [33]. On the other hand, Subagia et al. manufactured composite laminates containing $62 \mathrm{wt} . \%$ carbon and basalt fibers in an epoxy matrix. Once again, carbon fiber composites offered a flexural strength of about 800-900 $\mathrm{MPa}$ and a flexural modulus of $55 \mathrm{GPa}$ which are substantially higher to those obtained for slate-ELO composites. With regard to basalt fiber composites, tensile strength and flexural modulus values were 400-500 $\mathrm{MPa}$ and 25 GPa respectively [34]. However, Chairmain et al. obtained composite structures with epoxy matrix and glass (57.76 wt.\%) and basalt (53.38 wt.\%) fibers with tensile strength 
values of $250 \mathrm{MPa}$ and $325 \mathrm{MPa}$ for glass and basalt respectively which are slightly lower than those offered by slate-ELO composites [10].

\subsection{Analysis of the fractured surface.}

Cryofractured surfaces of ELO-slate composite laminates were observed by scanning electron microscopy (SEM) to evaluate the effectiveness of the different coupling agents in terms of the fiber-matrix interface phenomena. All SEM images in Fig. 4 show fractured fibers embedded into the polymeric ELO matrix; the morphology of the interface area between the fiber and the matrix could give an idea of the interactions and the role of the coupling agents in improving mechanical response as described before. Fig. 4a shows the fractured surface corresponding to the ELO-slate composite laminate without coupling agent treatment. We can clearly observe a gap between the fiber and the surrounding matrix indicating the poor interaction and compatibility between the organic polymer matrix derived from vegetable oils and the inorganic reinforcement (the liquid resin is not able to wet the fiber surface and this is evidenced by the presence of a gap between them). This poor interaction is responsible for the poor load transfer from matrix to fiber and, consequently, for the lower mechanical performance of the composite laminates without coupling agent as described before. In this case the discontinuities (gaps) formed between the matrix and the fiber act as stress concentrators promoting early failure and embrittlement of the composite laminates. SEM images corresponding to cryofractured surfaces of the composite laminates with different coupling agents show a remarkable increase in the interactions between the coupled slate fiber and the polymer matrix. The fractured surfaces are clearly different from Fig. 4a as the gap between matrix and fibers are now

barely observed. In the case of the amino-silane (ELO-slate A) sample (Fig. 4b), we 
observe a continuity in the area surrounding the fiber indicating good wetting properties of the polymer matrix on the fiber due to the presence of the coupling agent and the reaction of the amino functionality with the oxirane groups. For this reason, the coupling agent acts as a bridge between the inorganic component (slate fiber) and the organic component (epoxidized vegetable oil). Similar considerations apply to the composites with slate fiber treated with glycidyl silane (ELO-slate B) with marked fiber-matrix continuity (Fig.4c). In the case of the composite with the zirconate (ELOslate C) matrix (Fig. 4d), the fractured surface is slightly different but the presence of a rough surface on the fractured fiber is clearly detected indicating that the failure of the composite occurs by matrix fracture instead of fiber pull-out. Therefore, the rough surface of the fiber is an indication of the good matrix-fiber adhesion. Finally, Fig. 4e shows the cryofractured surface corresponding to composite laminates with previous treatment with the titanate coupling agent and once again we observe a good overall continuity in the fiber surroundings. These images are in total agreement with the previously discussed results since mechanical properties are remarkably improved in all composites produced with fibers treated with coupling agents. Therefore, the obtained results demonstrated that coupling agents play a key role in slate fiber-matrix interactions allowing good wetting properties which, in turn, lead to good fiber-matrix continuity and with evident positive effects on the mechanical performance of the composites prepared with ELO matrix and slate fabrics.

\section{Figure 4}




\section{Conclusions.}

This research has demonstrated the ability of Resin Transfer Molding (RTM) as industrially scalable manufacturing process for innovative composites based on a biobased epoxy resin derived from linseed oil and new reinforcements derived from slate wastes. In particular, the use of epoxidized linseed oil as base matrix for the manufacturing of composite laminate gives excellent results in terms of processing parameters and final properties. In the case of the epoxidized linseed oil (ELO), oxirane rings are not located in terminal positions so that the reactivity is slightly lower than conventional DGEBA epoxy resins; but the use of hydroxyl compounds as initiators (i.e. propanediol) and accelerators such as 1-methyl imidazole in combination of crosslinkers such as cyclic anhydrides gives interesting industrial formulations which can be crosslinked at moderate temperatures in the range $90-110{ }^{\circ} \mathrm{C}$ with balanced processing and curing cycles.

On the other hand the use of epoxidized linseed oil matrix and fibers from slate industry wastes provide a marked environmental benefit associated to the production of these innovative composite laminates. The siliceous structure of the slate fiber allows the adoption of well-established surface treatments with different coupling agents (silanes, titanates, and zirconates) with overall improved properties. The use of conventional glycidyl-silanes leads to the best mechanical performance of the studied ELO-slate composite laminates. In general terms, this research demonstrates that new environmentally friendly composite laminates with attracting mechanical performance can be obtained by Resin Transfer Molding (RTM) of a bio-derived epoxy resin from epoxidized linseed oil and slate fabrics obtained with fibers derived from slate wastes and these fiber can compete with conventional glass and basalt fibers with interesting balanced properties. ELO-slate composites could compete with conventional glass and 
basalt fiber reinforced composite laminates as the overall mechanical properties and they represent an environmentally friendly solution. Nevertheless, ELO-slate composite laminates are far away from high performance composite laminates such as those based on carbon, aramids and other high performance fibers.

\section{Acknowledgements.}

This study has been funded by the "Conselleria d'Educació, Cultura i Esport" Generalitat Valenciana (reference number: GV/2014/008). Authors thank Microscopy Services at UPV for helping in using SEM technique. 


\section{REFERENCES}

1. Campos, P.L., et al., Alkali-silica and alkali-silicate reactivity in slates. Estudios Geologicos-Madrid, 2010. 66(1): p. 91-98.

2. de Carvalho, G.M.X., et al., Composites obtained by the combination of slate powder and polypropylene. Polimeros-Ciencia E Tecnologia, 2007. 17(2): p. 98103.

3. Rodriguez, M.A., et al., Study of the reaction of gammamethacryloxypropyltrimethoxysilane (gamma-MPS) with slate surfaces. Journal of Materials Science, 1999. 34(16): p. 3867-3873.

4. Rodriguez, M.A., et al., Study of the reaction of gamma-aminopropyltriethoxy silane with slate particles. Boletin De La Sociedad Espanola De Ceramica Y Vidrio, 2001. 40(2): p. 101-106.

5. Barluenga, G. and F. Hernandez-Olivares, Self-levelling cement mortar containing grounded slate from quarrying waste. Construction and Building Materials, 2010. 24(9): p. 1601-1607.

6. Frias, M., et al., Scientific and technical aspects of blended cement matrices containing activated slate wastes. Cement \& Concrete Composites, 2014. 48: p. $19-25$.

7. Deak, T. and T. Czigany, Chemical Composition and Mechanical Properties of Basalt and Glass Fibers: A Comparison. Textile Research Journal, 2009. 79(7): p. $645-651$.

8. Walsh, J.A., The use of the scanning electron microscope in the determination of the mineral composition of Ballachulish slate. Materials Characterization, 2007. 58(11-12): p. 1095-1103. 
9. Wei, B., H. Cao, and S. Song, Environmental resistance and mechanical performance of basalt and glass fibers. Materials Science and Engineering aStructural Materials Properties Microstructure and Processing, 2010. 527(1819): p. 4708-4715.

10. Chairman, C.A. and S.P.K. Babu, Mechanical and abrasive wear behavior of glass and basalt fabric-reinforced epoxy composites. Journal of Applied Polymer Science, 2013. 130(1): p. 120-130.

11. Militky, J., V. Kovacic, and J. Rubnerova, Influence of thermal treatment on tensile failure of basalt fibers. Engineering Fracture Mechanics, 2002. 69(9): p. 1025-1033.

12. Espana, J.M., et al., Investigation of the effect of different silane coupling agents on mechanical performance of basalt fiber composite laminates with biobased epoxy matrices. Polymer Composites, 2013. 34(3): p. 376-381.

13. Petrucci, R., et al., Mechanical characterisation of hybrid composite laminates based on basalt fibres in combination with flax, hemp and glass fibres manufactured by vacuum infusion. Materials \& Design, 2013. 49: p. 728-735.

14. Sfarra, S., et al., Falling weight impacted glass and basalt fibre woven composites inspected using non-destructive techniques. Composites Part BEngineering, 2013. 45(1): p. 601-608.

15. Yan, J.H., B.H. Gu, and B.Z. Sun, Dynamic response and stability of basalt woven fabric composites under impulsive compression. Journal of Reinforced Plastics and Composites, 2013. 32(2): p. 137-144.

16. Bai, S., et al., Improving the adhesion between carbon fibres and an elastomer matrix using an acrylonitrile containing atmospheric plasma treatment. Composite Interfaces, 2013. 20(9): p. 761-782. 
17. Cech, V., et al., Enhanced interfacial adhesion of glass fibers by tetravinylsilane plasma modification. Composites Part a-Applied Science and Manufacturing, 2014. 58: p. 84-89.

18. Krasny, I., et al., The effect of low temperature air plasma treatment on physicochemical properties of kaolinite/polyethylene composites. Composites Part BEngineering, 2014. 59: p. 293-299.

19. Moaseri, E., M. Maghrebi, and M. Baniadam, Improvements in mechanical properties of carbon fiber-reinforced epoxy composites: A microwave-assisted approach in functionalization of carbon fiber via diamines. Materials \& Design, 2014. 55: p. 644-652.

20. Zhou, M., et al., Interfacial crystallization enhanced interfacial interaction of Poly (butylene succinate)/ramie fiber biocomposites using dopamine as a modifier. Composites Science and Technology, 2014. 91: p. 22-29.

21. Choi, S., et al., Effect of silane coupling agent on the durability of epoxy adhesion for structural strengthening applications. Polymer Engineering and Science, 2013. 53(2): p. 283-294.

22. Samal, S.K., et al., Bio-based Polyethylene-Lignin Composites Containing a Pro-oxidant/Pro-degradant Additive: Preparation and Characterization. Journal of Polymers and the Environment, 2014. 22(1): p. 58-68.

23. Espinoza-Perez, J.D., et al., Comparison of Curing Agents for Epoxidized Vegetable Oils Applied to Composites. Polymer Composites, 2011. 32(11): p. 1806-1816.

24. Battegazzore, D., J. Alongi, and A. Frache, Poly(lactic acid)-Based Composites Containing Natural Fillers: Thermal, Mechanical and Barrier Properties. Journal of Polymers and the Environment, 2014. 22(1): p. 88-98. 
25. Bajpai, P.K., I. Singh, and J. Madaan, Development and characterization of PLA-based green composites: A review. Journal of Thermoplastic Composite Materials, 2014. 27(1): p. 52-81.

26. Khot, S.N., et al., Development and application of triglyceride-based polymers and composites. Journal of Applied Polymer Science, 2001. 82(3): p. 703-723.

27. Miyagawa, H., et al., Thermo-physical and impact properties of epoxy containing epoxidized linseed oil, 2(a) - Amine-cured epoxy. Macromolecular Materials and Engineering, 2004. 289(7): p. 636-641.

28. Miyagawa, H., et al., Thermo-physical and impact properties of epoxy containing epoxidized linseed oil, 1 - Anhydride-cured epoxy. Macromolecular Materials and Engineering, 2004. 289(7): p. 629-635.

29. Samper, M.D., et al., Thermal and Mechanical Characterization of Epoxy Resins (ELO and ESO) Cured with Anhydrides. Journal of the American Oil Chemists Society, 2012. 89(8): p. 1521-1528.

30. Fejos, M., J. Karger-Kocsis, and S. Grishchuk, Effects of fibre content and textile structure on dynamic-mechanical and shape-memory properties of ELO/flax biocomposites. Journal of Reinforced Plastics and Composites, 2013. 32(24): p. 1879-1886.

31. Temiz, A., et al., Effect of bio-oil and epoxidized linseed oil on physical, mechanical, and biological properties of treated wood. Journal of Applied Polymer Science, 2013. 130(3): p. 1562-1569.

32. Fombuena, V., et al., Study of the Properties of Thermoset Materials Derived from Epoxidized Soybean Oil and Protein Fillers. Journal of the American Oil Chemists Society, 2013. 90(3): p. 449-457. 
33. Guermazi, N., et al., Investigations on the fabrication and the characterization of glass/epoxy, carbon/epoxy and hybrid composites used in the reinforcement and the repair of aeronautic structures. Materials \& Design, 2014. 56: p. 714724.

34. Subagia, I., et al., Effect of stacking sequence on the flexural properties of hybrid composites reinforced with carbon and basalt fibers. Composites Part BEngineering, 2014. 58: p. 251-258.

35. Tao, Q., et al., Effect of functionalized kaolinite on the curing kinetics of cycloaliphatic epoxy/anhydride system. Applied Clay Science, 2014. 95: p. 317322.

36. Karger-Kocsis, J., et al., Curing, Gelling, Thermomechanical, and Thermal Decomposition Behaviors of Anhydride-Cured Epoxy (DGEBA)/Epoxidized Soybean Oil Compositions. Polymer Engineering and Science, 2014. 54(4): p. 747-755. 


\section{Figure legends}

Figure 1.- Dynamic differential scanning calorimetry (DSC) curing profile of thermosetting resin based on epoxidized linseed oil (ELO).

Figure 2.- Evolution of the curing profiles of epoxidized linseed oil (ELO) with methyl nadic anhydride (MNA) obtained by oscillatory rheometry at different isothermal curing temperatures: a) $90^{\circ} \mathrm{C}$, b) $100{ }^{\circ} \mathrm{C}$, c) $110^{\circ} \mathrm{C}$ and d) $120^{\circ} \mathrm{C}$.

Figure 3.- Estimation of the apparent activation energy (Ea) by linear adjust of the plot representation of $\operatorname{Ln}\left(\mathrm{t}_{\mathrm{gel}}\right)$ vs 1000/T.

Figure 4.- SEM images of cryofractured surfaces of ELO-slate composite laminates with different coupling agents a) without coupling agent (ELO-slate TT), b) aminosilane (ELO-slate A), c) glycidyl-silane (ELO-slate B), d) zirconate (ELO-slate C) and e) titanate (ELO-slate D). 
Table 1.- Process conditions of ELO-slate fabric composites manufactured by Resin Transfer Molding (RTM).

\begin{tabular}{|c|c|c|}
\hline \multicolumn{2}{|l|}{ Parameter } & Value \\
\hline \multicolumn{2}{|c|}{ Resin Injection temperature $\left({ }^{\circ} \mathrm{C}\right)$} & 60 \\
\hline \multicolumn{2}{|c|}{ Resin injection pressure $(\mathrm{kPa})$} & 100 \\
\hline \multicolumn{2}{|c|}{ In mould cavity pressure $(\mathrm{kPa})$} & 95 \\
\hline \multirow{2}{*}{ Curing cycle } & Temperature $\left({ }^{\circ} \mathrm{C}\right)$ & 100 \\
\hline & Time (h) & 3.0 \\
\hline \multicolumn{2}{|c|}{ Demolding temperature $\left({ }^{\circ} \mathrm{C}\right)$} & 30 \\
\hline
\end{tabular}


Table 2.- Summary of the mechanical properties (tensile, flexural and Charpy's impact tests) of ELO-slate composite laminates in terms of the coupling agent.

\begin{tabular}{|l|c|l|c|c|c|}
\hline Samples & $\begin{array}{c}\text { Tensile strength } \\
(\mathbf{M P a})\end{array}$ & $\begin{array}{c}\text { Elastic modulus } \\
(\mathbf{G P a})\end{array}$ & $\begin{array}{c}\text { Flexural strength } \\
(\mathbf{M P a})\end{array}$ & Flexural modulus (GPa) & $\begin{array}{c}\text { Charpy Impact } \\
\left.\text { Energy (kJ m }{ }^{-2}\right)\end{array}$ \\
\hline ELO-SlateTT & $328.9(8.3)^{\mathrm{a}}$ & $21.9(0.6)^{\mathrm{a}}$ & $299.2(28.3)^{\mathrm{a}}$ & $18.4(0.9)^{\mathrm{a}}$ & $66.0(6.3)^{\mathrm{a}}$ \\
\hline ELO-Slate A & $351.8(22.1)^{\mathrm{a}}$ & $24.7(1.4)^{\mathrm{a}, \mathrm{b}}$ & $336.6(34.5)^{\mathrm{a}, \mathrm{b}}$ & $18.6(1.5)^{\mathrm{a}}$ & $75.2(4.6)^{\mathrm{a}}$ \\
\hline ELO-Slate B & $359.1(20.3)^{\mathrm{a}}$ & $25.6(2.7)^{\mathrm{b}}$ & $402.1(61.9)^{\mathrm{b}}$ & $19.7(2.4)^{\mathrm{a}}$ & $77.9(2.6)^{\mathrm{a}}$ \\
\hline ELO-Slate C & $328.2(14.0)^{\mathrm{a}}$ & $23.7(1.4)^{\mathrm{a}, \mathrm{b}}$ & $354.2(57.0)^{\mathrm{a}, \mathrm{b}}$ & $19.2(0.4)^{\mathrm{a}}$ & $69.4(4.1)^{\mathrm{a}}$ \\
\hline ELO-Slate D & $358.5(13.9)^{\mathrm{a}}$ & $25.2(1.4)^{\mathrm{b}}$ & $389.7(46.9)^{\mathrm{b}}$ & $19.6(0.4)^{\mathrm{a}}$ & $78.2(4.3)^{\mathrm{a}}$ \\
\hline
\end{tabular}

Values between parentheses correspond to the standard deviation.

${ }^{a-b}$ Different superscripts within the same column indicate significant differences between formulations $(p<0.05)$. 
Figure 1.- Dynamic differential scanning calorimetry (DSC) curing profile of thermosetting resin based on epoxidized linseed oil (ELO).

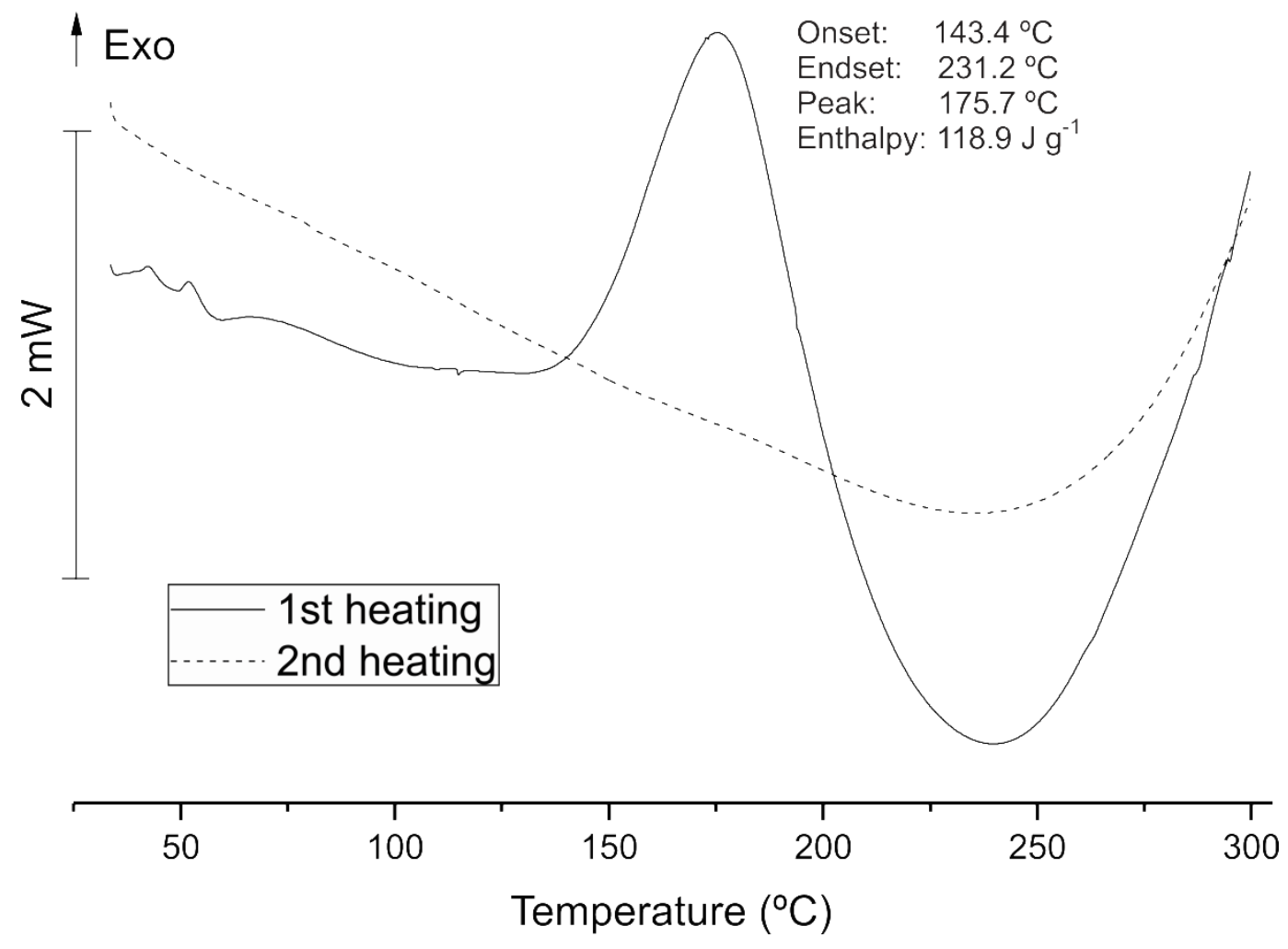


Figure 2.- Evolution of the curing profiles of epoxidized linseed oil (ELO) with methyl nadic anhydride (MNA) obtained by oscillatory rheometry at different isothermal curing temperatures:

a) $90{ }^{\circ} \mathrm{C}$, b) $100{ }^{\circ} \mathrm{C}$, c) $110{ }^{\circ} \mathrm{C}$ and d) $120^{\circ} \mathrm{C}$.

a)

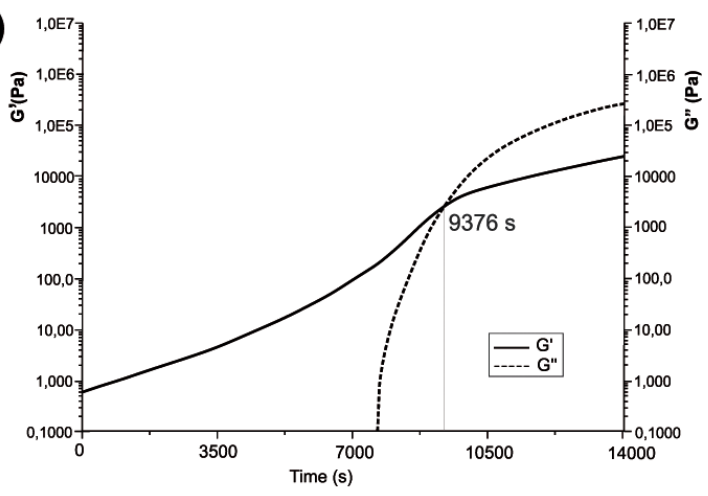

c)

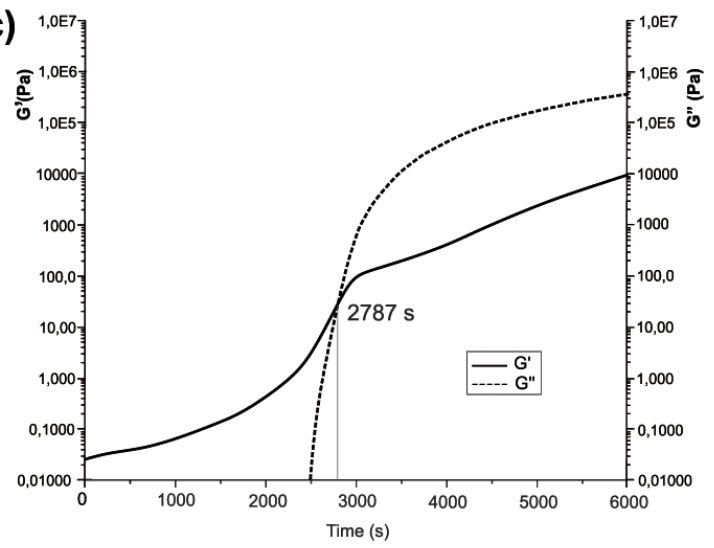

b) 1

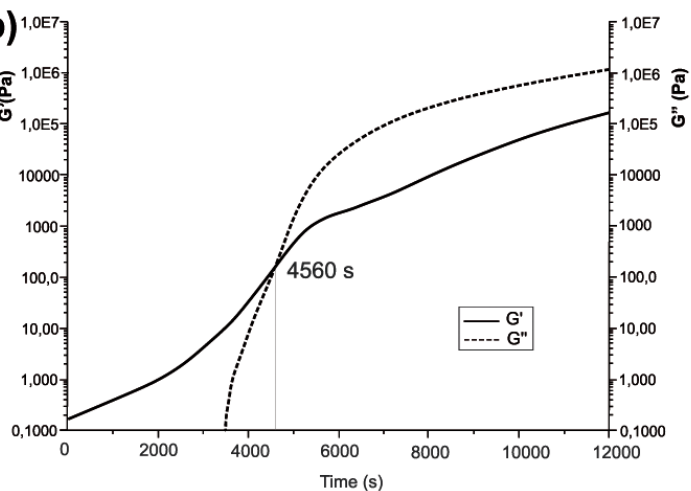

d)

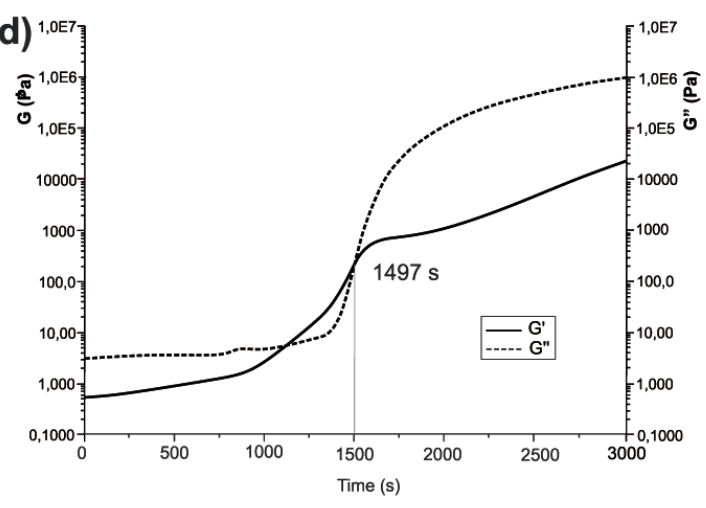


Figure 3.- Estimation of the apparent activation energy (Ea) by linear adjust of the plot representation of Ln (tgel) vs 1000/T.

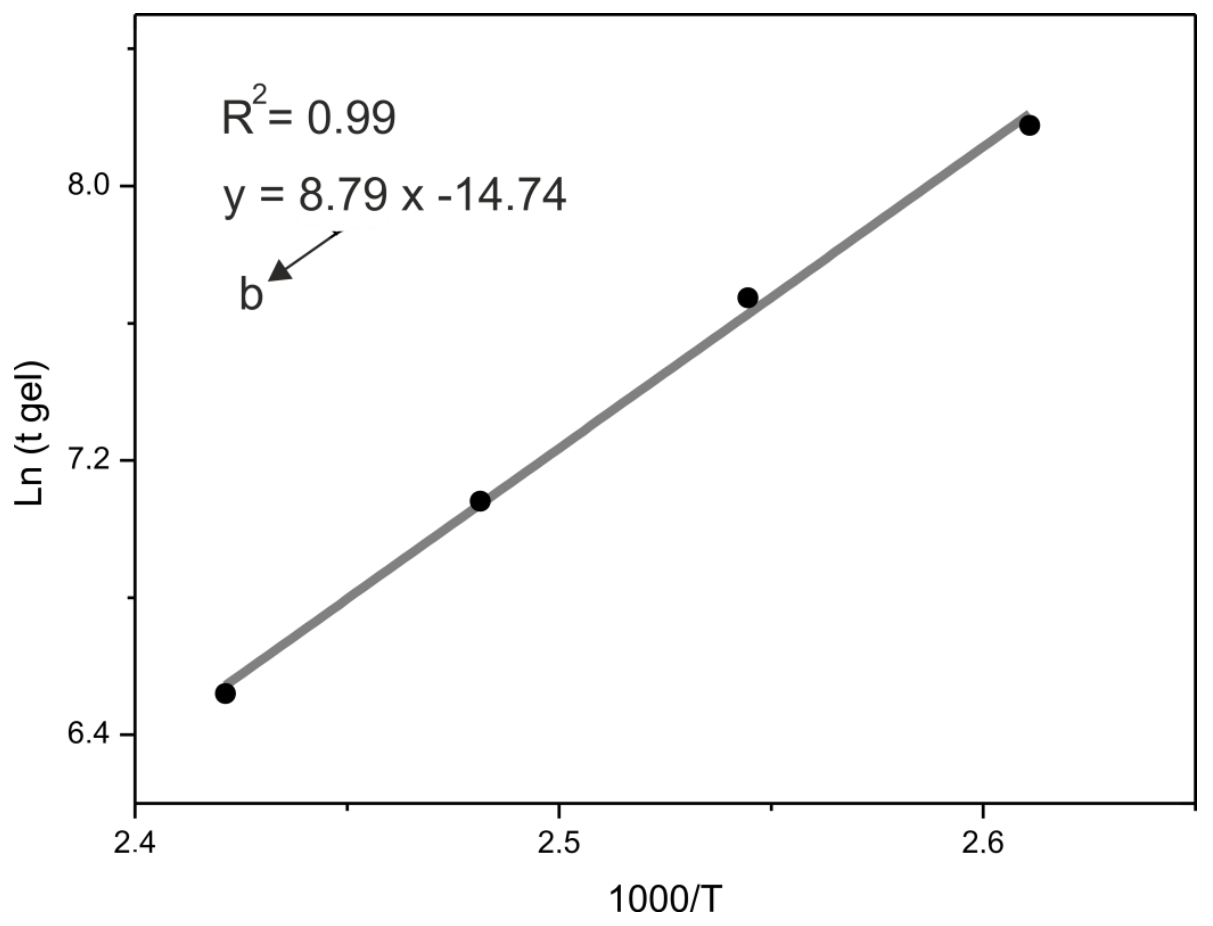


Figure 4.- SEM images of cryofractured surfaces of ELO-slate composite laminates with different coupling agents a) without coupling agent (ELO-slate TT), b) amino-silane (ELO-slate A), c) glycidyl-silane (ELO-slate B), d) zirconate (ELO-slate C) and e) titanate (ELO-slate D).
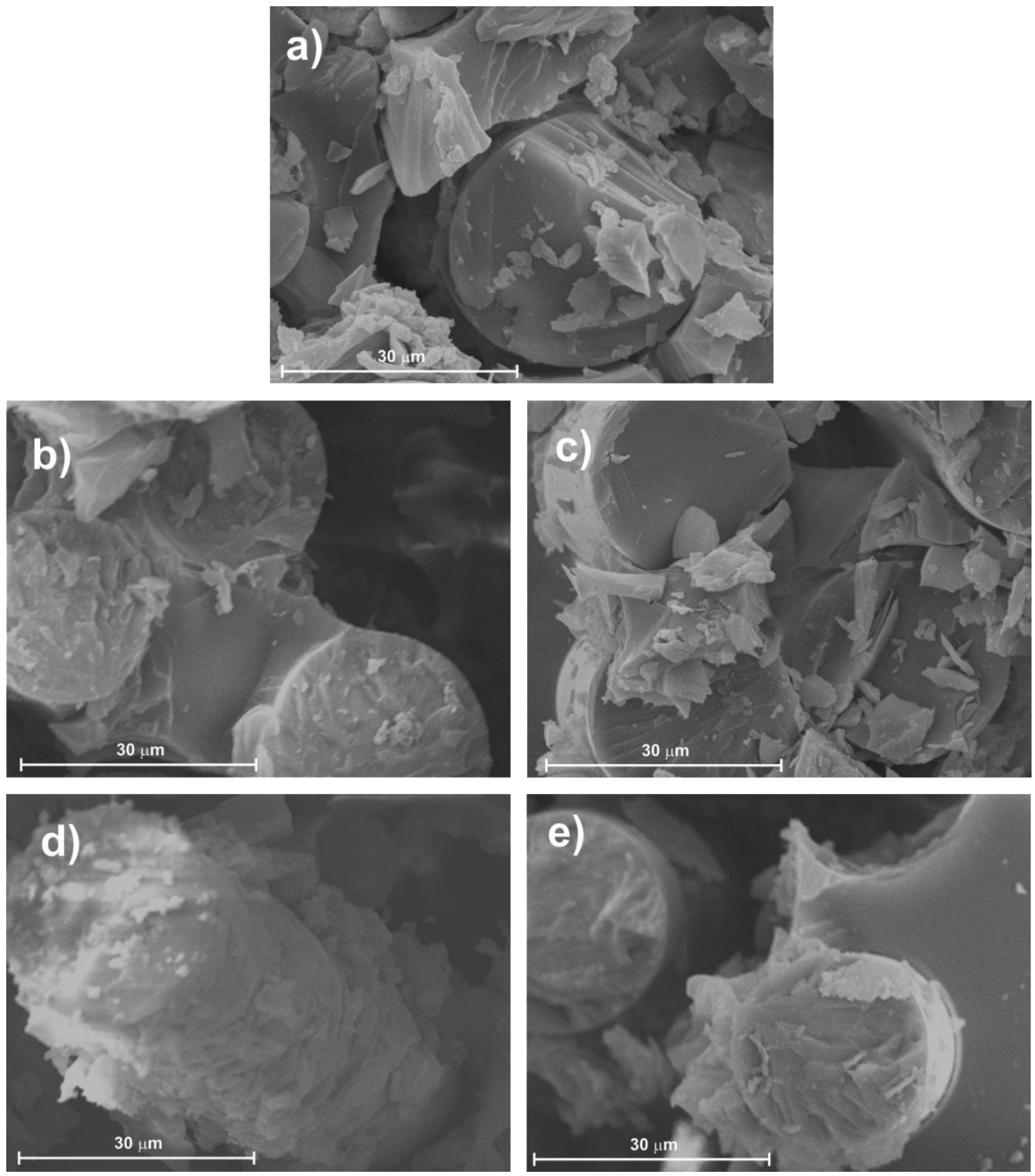